\title{
A horizontally polarizing liquid trap enhances the tabanid-capturing efficiency of the classic canopy trap
}

\author{
${ }_{1}$ Á. Egri ${ }^{1}$, M. Blahó ${ }_{5}^{1}$, D. Száz , ${ }_{5}$ G. Kriska ${ }^{2,3}$, J. Majer, \\ T. Herczeg, M. Gyurkovszky, R. Farkas and G. Horváth * \\ 'Environmental Optics Laboratory, Department of Biological Physics, Physical \\ Institute, Eötvös University, H-1117 Budapest, Pázmány sétány 1, Hungary: \\ 'Group for Methodology in Biology Teaching, Biological Institute, Eötvös \\ University, H-1117 Budapest, Pázmány sétány 1, Hungary: 'Danube Research \\ Institute, Centre for Ecological Research, Hungarian Academy of Sciences, \\ Alkotmány út 2-4., H-2163 Vácrátót, Hungary: ${ }^{4}$ Department of General and \\ Applied Ecology, Institute of Environment Studies, University of Pécs, Ifjúság \\ útja 6, H-7624 Pécs, Hungary: ${ }^{5}$ Department of Parasitology and Zoology, Faculty \\ of Veterinary Science, Szent István University, H-1078 Budapest, István utca 2, \\ Hungary
}

\begin{abstract}
Host-seeking female tabanid flies, that need mammalian blood for the development of their eggs, can be captured by the classic canopy trap with an elevated shiny black sphere as a luring visual target. The design of more efficient tabanid traps is important for stockbreeders to control tabanids, since these blood-sucking insects can cause severe problems for livestock, especially for horse-and cattle-keepers: reduced meat/milk production in cattle farms, horses cannot be ridden, decreased quality of hides due to biting scars. We show here that male and female tabanids can be caught by a novel, weather-proof liquidfilled black tray laid on the ground, because the strongly and horizontally polarized light reflected from the black liquid surface attracts water-seeking polarotactic tabanids. We performed field experiments to reveal the ideal elevation of the liquid trap and to compare the tabanid-capturing efficiency of three different traps: (1) the classic canopy trap, (2) the new polarization liquid trap, and (3) the combination of the two traps. In field tests, we showed that the combined trap captures 2.4-8.2 times more tabanids than the canopy trap alone. The reason for the larger efficiency of the combined trap is that it captures simultaneously the host-seeking female and the water-seeking male and female tabanids. We suggest supplementing the traditional canopy trap with the new liquid trap in order to enhance the tabanid-capturing efficiency.
\end{abstract}

Keywords: horsefly, tabanid fly, canopy trap, liquid trap, light polarization, polarotaxis

(Accepted 29 May 2013; First published online 28 June 2013)

*Author for correspondence

Phone: +0036 30-64-64-371

Fax: +0036 1-372-2757 E-

mail: gh@arago.elte.hu 

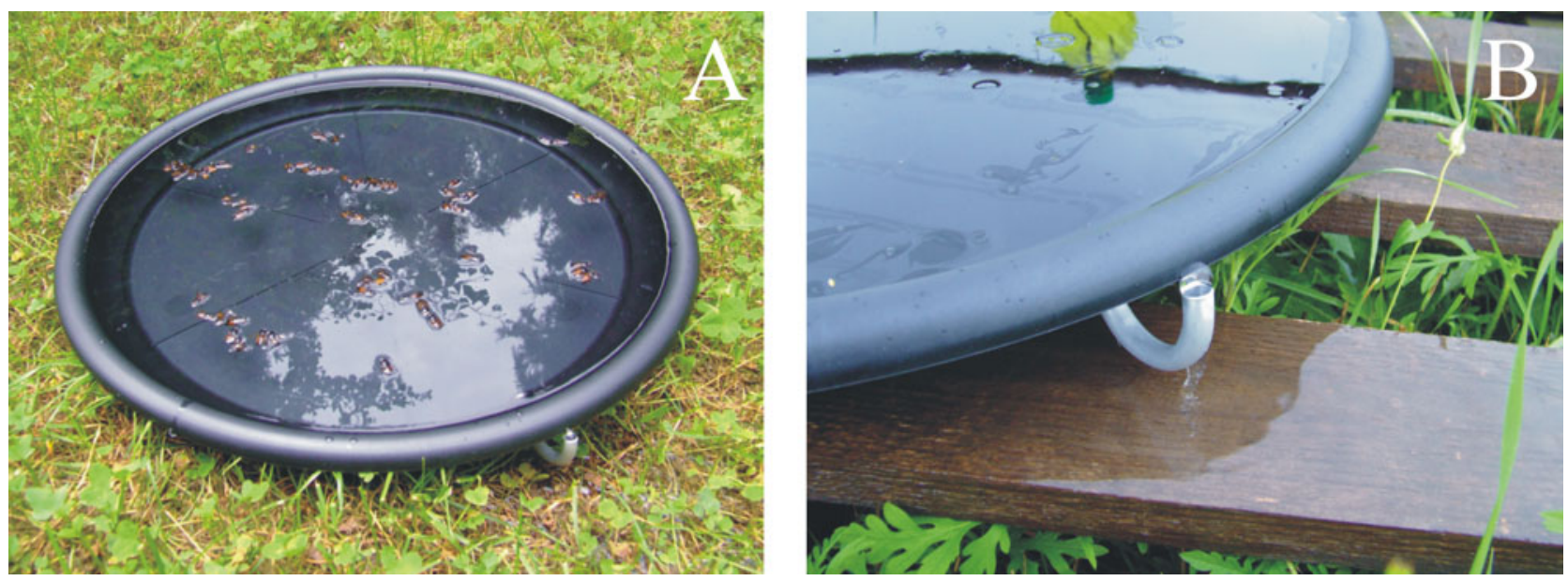

Fig. 1. Left: The new polarization liquid trap composed of a circular black plastic tray (with a diameter of $50 \mathrm{~cm}$ ) possessing an aluminium overflow tube. The tray should be filled with 2 litres tap water until the surplus water flows out the overflow tube, then 1 litre vegetable oil is poured onto the water. Right: Close-up photograph of the overflow tube, through which the surplus water is flowing out.

\section{Introduction}

In regions where tabanid flies are abundant, livestock, especially cattle and horses can be strongly annoyed by the constant attacks of blood-sucking tabanid females. Thus, the host animals' ability to graze is disrupted. The consequences of this are that meat and/or milk production is reduced in cattle farms, and horses cannot be ridden (Hunter \& Moorhouse, 1976; Harris et al., 1987; Lehane, 2005). Furthermore, tabanid bites cause visible scars on the cattle skin. The bigger the scarless area of cattle hides, the higher their values. Numerous tabanid bites can drastically lower the value of cattle bred for hide. Tabanid females also vector the pathogens of several diseases (e.g. tularaemia, anaplasmosis, hog cholera, equine infectious anaemia, filariasis, anthrax, Lyme disease) and induce allergic reactions when sucking blood (Foil, 1989; Luger, 1990; MaatBleeker \& van Bronswijk, 1995; Veer, et al., 2002; Lehane, 2005). Because of these problems, effective tabanid control traps are in high demand, especially for stock-breeders. Scientists studying the biology and ecology of tabanid flies also need appropriate tabanid traps. It is, therefore, important to develop tabanid traps, which can be beneficial in all regions of the world where tabanids occur in abundance (e.g. between the latitudes of $\pm 60^{\circ}$ ).

Nowadays the most widespread tabanid trap type is the canopy trap. It is essentially a conical/pyramidal canopy resting on a tripod/tetrapod, or hanging from a large vertical hook stuck into the ground with an insect collector fitted at its apex (MuirheadThomson, 1991, p. 215). Suspended beneath the canopy is the visually attractant decoy target in the form of a shiny black sphere (Bracken et al., 1962; Thorsteinson et al., 1965). The efficacy of this trap type has been frequently demonstrated (MuirheadThomson, 1991, p. 216). Its tabanid-capturing efficiency can be enhanced by the addition of $\mathrm{CO}_{2}$ or certain other chemical attractants, e.g. ammonia, phenol, octenol or acetone (Hribar et al., 1992; Mihok, 2002; Mihok et al., 2006; Mihok \& Mulye, 2010; Mihok \& Lange, 2012). However, the canopy trap captures only host-seeking female tabanids attracted to the shiny black sphere, because this visual target imitates the dark silhouette of a host animal (Muirhead-Thomson, 1991, p. 216).
Horváth et al.(2008) showed that male and female tabanids are attracted to horizontally polarized light, because these insects find water by the horizontal polarization of light reflected from the water surface. They emphasized that this polarotaxis can be the basis of the design of new and better tabanid traps composed of different kinds of horizontal black surfaces reflecting strongly and horizontally polarized light. The attracted tabanids can be captured by oil-filled trays, for example, a method used frequently in choice experiments with scientific purposes (Horváth \& Kriska, 2008; Horváth et al., 2010a, b; Blahó et al., 2012a, b; Egri et al., 2012a, b). Kriska et al.(2009) showed that the darker a colourless (white, grey, black), shiny, horizontally polarizing oil-filled tray laid on the ground is, the higher the degree of linear polarization $\mathrm{d}$ of oil-reflected light is, and thus, the greater is its attractiveness to tabanids.

On the basis of these findings, we developed a new polarization tabanid trap composed of a black liquid-filled tray. In this work we describe this new polarization liquid trap, being a concrete realization of the concept suggested by Horváth et al.(2008). We show here that male and female tabanids can be caught by our weather-proof, liquid-filled, black tray laid on the ground, because the strongly and horizontally polarized light reflected from the black liquid surface is very attractive to water-seeking polarotactic tabanids. In field experiments, we established the ideal elevation of the liquid trap: the liquid trap should be placed on the ground to ensure its maximal efficacy. Then, to compare the tabanidcapturing efficiency of the classic canopy trap, the new polarization liquid trap, and the combination of the two traps, we performed further field experiments.

\section{Materials and methods \\ Polarization liquid trap}

Our new trap is essentially a circular black plastic tray (with a diameter of $50 \mathrm{~cm}$ ) possessing an overflow tube (fig. 1). Every black tray was filled with 2 litres tap water, and then 1litre common vegetable oil was poured onto the water. As oil 


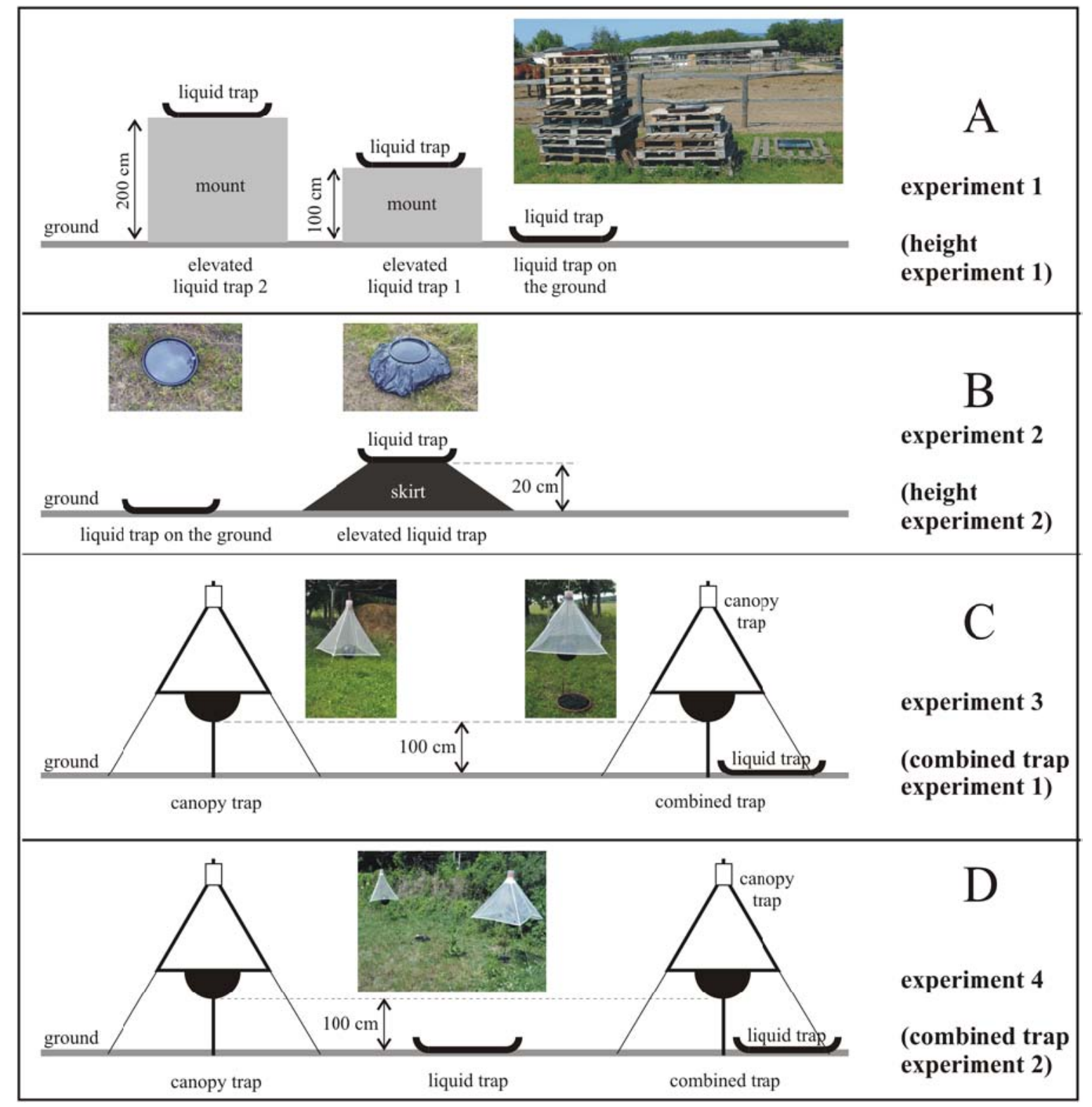

Fig. 2. Schematic drawings of the arrangements of the different tabanid traps used in our field experiments. Insets: photographs of the different traps. We conducted two different types of field experiment: height experiment to reveal the ideal elevation of the liquid trap (A,B), and combined trap experiment to compare the tabanid-capturing efficiency of canopy traps, liquid traps and their combinations (C,D).

is less dense than water, it sits in a thin layer on the water. In rain, surplus water collected in the tray flowed out through the overflow tube (fig. 1B). The result was an always ideally horizontal black liquid surface, which reflected strongly and horizontally polarized light, and thus attracted polarotactic tabanids.

We conducted two different types of field experiment (fig. 2): height experiment (fig. 2A,B) and combined trap experiment (fig. 2C,D). In the former, the influence of height of the liquid trap from the ground on the tabanid-capturing efficiency was studied, while in the latter, the tabanid-catching efficiencies of canopy traps, liquid traps and combined traps were compared.
Experiment 1 (height experiment 1)

This experiment was performed on a Hungarian horse farm in Göd $\left(47^{\circ} 43^{\prime} \mathrm{N}, 19^{\circ} 09^{\prime} \mathrm{E}\right)$ between 28 June and 28 August 2009. This horse farm was chosen, since in our earlier similar field experiments (Kriska et al., 2009; Horváth et al., 2010a, b; Blahó et al., 2012a, b; Egri et al., 2012a, b, 2013) we have experienced an abundance of tabanid flies in every summer. Three vegetable-oilfilled black trays $(50 \mathrm{~cm} \times 50 \mathrm{~cm}$, manufacturer: MFKK Invention and Research Center Services Co. Ltd, Budapest, Hungary) were positioned at heights of $0 \mathrm{~m}$ (ground), 1 and $2 \mathrm{~m}$ from the ground 2 $\mathrm{m}$ apart horizontally along a straight line (fig. 2A). The tabanids trapped by these 
Table 1. Species, sex and number of tabanid flies captured by the polarization liquid traps positioned at three different heights in experiment 1 at Göd (fig. 2A).

\begin{tabular}{lccc} 
Species and sex & \multicolumn{3}{c}{ Height of trap } \\
& $0 \mathrm{~m}$ & $1 \mathrm{~m}$ & $2 \mathrm{~m}$ \\
\hline & & & \\
$\begin{array}{l}\text { Tabanus bromius, male T. } \\
\text { bromius, female Tabanus } \\
\text { tergestinus, male T. } \\
\text { tergestinus, female Sum }\end{array}$ & 1010200140 & 00000 & 000 \\
& $360(100 \%)$ & $(0 \%)$ & $(0 \%)$
\end{tabular}

Table 2. Species, sex and number of tabanid flies trapped by the polarization liquid traps positioned at four different heights in experiment 1 (fig. 2A) at Tarnalelesz.

\begin{tabular}{|c|c|c|c|c|}
\hline \multirow[t]{2}{*}{ Species and sex } & \multirow[b]{2}{*}{$0 \mathrm{~m}$} & \multicolumn{3}{|c|}{ Height of trap } \\
\hline & & $0.5 \mathrm{~m}$ & $1.0 \mathrm{~m}$ & $\begin{array}{c}1.5 \\
\mathrm{~m}\end{array}$ \\
\hline Chrysops caecutiens, female & 0 & 0 & 1 & 0 \\
\hline Atylotus fulvus, male & 6 & 0 & 0 & 0 \\
\hline A. fulvus, female & 2 & 0 & 0 & 0 \\
\hline Atylotus loewianus, male & 8 & 0 & 0 & 0 \\
\hline A. loewianus, female & 8 & 0 & 0 & 0 \\
\hline $\begin{array}{l}\text { Heptatoma pellucens, } \\
\text { female }\end{array}$ & 1 & 0 & 0 & 0 \\
\hline T. bromius, male & 6 & 0 & 0 & 0 \\
\hline T. bromius, female & 1 & 0 & 0 & 0 \\
\hline Tabanus bovinus, male & 3 & 0 & 0 & 0 \\
\hline T. bovinus, female & 2 & 0 & 0 & 0 \\
\hline Tabanus maculicornis, male & 2 & 0 & 0 & 0 \\
\hline \multicolumn{2}{|c|}{ 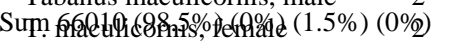 } & 0 & 0 & 0 \\
\hline $\mathrm{T}$. tergestinus, male & 11 & 0 & 0 & 0 \\
\hline T. tergestinus, female & 14 & 0 & 0 & 0 \\
\hline
\end{tabular}

trays (table 1) were collected weekly (when the order of the traps was randomly changed), stored in ethyl alcohol and identified later in the laboratory. This experiment was repeated in a garden next to a range at Tarnalelesz, Hungary ( $\left.48^{\circ} 3^{\prime} \mathrm{N}, 20^{\circ} 10^{\prime} \mathrm{E}\right)$ on the following days in the summer of 2009: 28-29 June; 5-6, 12-13, 26-31 July, 1-2 August (table 2). To half the height increment between the elevated traps from 1 to $0.5 \mathrm{~m}$, four vegetable-oil-filled quadratic black trays $(50 \mathrm{~cm} \times 50$ $\mathrm{cm}$ ) were positioned at heights of $0 \mathrm{~m}$ (ground),

0.5m, 1.0mand1.5m from theground2mapart horizontally.

\section{Experiment 2 (height experiment 2)}

This experiment was performed between 3 July and 4 September 2011 on the same horse farm as experiment

1. The aim of this experiment was twofold: (1) To test the influence of a relatively small elevation $(20 \mathrm{~cm})$ of the liquid trap on the tabanid-capturing efficiency. (2) To test whether a strongly and horizontally polarizing, sticky black annular plastic sheet around the liquid trap (called a 'skirt' hereinafter) can enhance the tabanid-capturing efficiency. Two circular (diameter $=50 \mathrm{~cm}$ ) black plastic trays were laid $10 \mathrm{~m}$ apart on the grassy ground (fig. 2B): The first tray was on the ground, and the second tray was elevated at a height of $20 \mathrm{~cm}$ from the ground positioned on the top of a truncated conical platform covered by a shiny black plastic sheet (skirt)
Table 3. Number of tabanids (T. tergestinus) trapped by the two polarization liquid traps in experiment 2 (fig. 2B) as a function of time. Trap 1 was on the ground. Trap 2 was elevated $+20 \mathrm{~cm}$ from the ground on the top of a sticky black truncated conical skirt.

\begin{tabular}{|c|c|c|}
\hline \multirow[t]{2}{*}{ Date (2011) } & \multirow[t]{2}{*}{ Trap 1 (on ground) } & Trap 2 (elevated) \\
\hline & & Periphery \\
\hline 9 July 15 & 100108111211158 & 822010200010 \\
\hline July 23 July & 265 (94.3\%) 265 (94.3\%) & \multirow{2}{*}{0014 (5.0\%) 2} \\
\hline 8 August & & \\
\hline \multicolumn{3}{|l|}{13 August } \\
\hline \multicolumn{3}{|l|}{27 August } \\
\hline \\
\hline \multicolumn{3}{|l|}{ September } \\
\hline \multicolumn{3}{|l|}{ Sum } \\
\hline Total & (150 female+ 115 male) & (11 female + 5 male) \\
\hline
\end{tabular}

lubricated with insect-monitoring glue (BábolnaBio mouse trapping glue, Hungary). The function of the skirt was to enhance the visibility of the liquid trap, since the skirt can be seen by flying tabanids already from a remote distance, not like the flat liquid surface. Both black trays were filled with tap water and vegetable oil on the water surface. The tabanids trapped by these two trays were collected periodically (days of collection are given in table 3) when the sites of the two traps were reversed.

\section{Experiment 3 (combined trap experiment 1)}

This experiment was performed between 19 July and 25 September 2010 on a Hungarian horse farm in Szokolya (47 $52^{\prime}$ $\mathrm{N}, 19^{\circ} 00^{\prime} \mathrm{E}$ ), where tabanids are abundant in summer (Kriska et al., 2009; Horváth et al., 2010a, b; Blahó et al., 2012a, b; Egri et al., 2012a, b, 2013). Our aim was to compare the tabanidcapturing efficiency of a conventional canopy trap and a combined trap (fig. 2C). The latter was composed of a conventional canopy trap and a liquid trap. Both canopy traps were composed of a white pyramidal canopy made from a common tulle and a shiny black beach ball sprayed by black paint with a diameter of $50 \mathrm{~cm}$ at a height of $1 \mathrm{~m}$ from the ground. In the combined trap the liquid trap was a circular (diameter $=80 \mathrm{~cm}$ ) blackplastic tray laid on the grassy ground below the canopy and filled with water and vegetable oil as described above (see Polarization liquid trap). The tabanids trapped by both traps were collected weekly when the sites of the two traps were reversed.

\section{Experiment 4 (combined trap experiment 2)}

This experiment was performed between 15 June and 12 September 2012 on the same horse farm as experiment 3 . The aim of this experiment was to determine whether a combined trap captures more tabanids than its component traps alone. Therefore, we compared the tabanid-capturing efficiencies of the following three traps (fig. 2D): (i) A conventional canopy trap with a shiny black sphere ( $50 \mathrm{~cm}$ diameter beach ball sprayed by a black paint) at a height of $1 \mathrm{~m}$ from the ground below a pyramidal canopy composed of a common white tulle. (ii) A liquid trap composed of a circular black tray (diameter $=50 \mathrm{~cm}$ ) placed on the ground. The tray was filled with 2 litres tap water and 1 litre common vegetable oil on the 
Table 4. Species, sex and number of tabanids captured by the different traps (canopy trap with an aerial shiny black sphere, polarization liquid trap on the ground, combined trap: canopy trap together with liquid trap) in experiment 4 (figs $2 \mathrm{D}$ and 3). m: male, f: female.

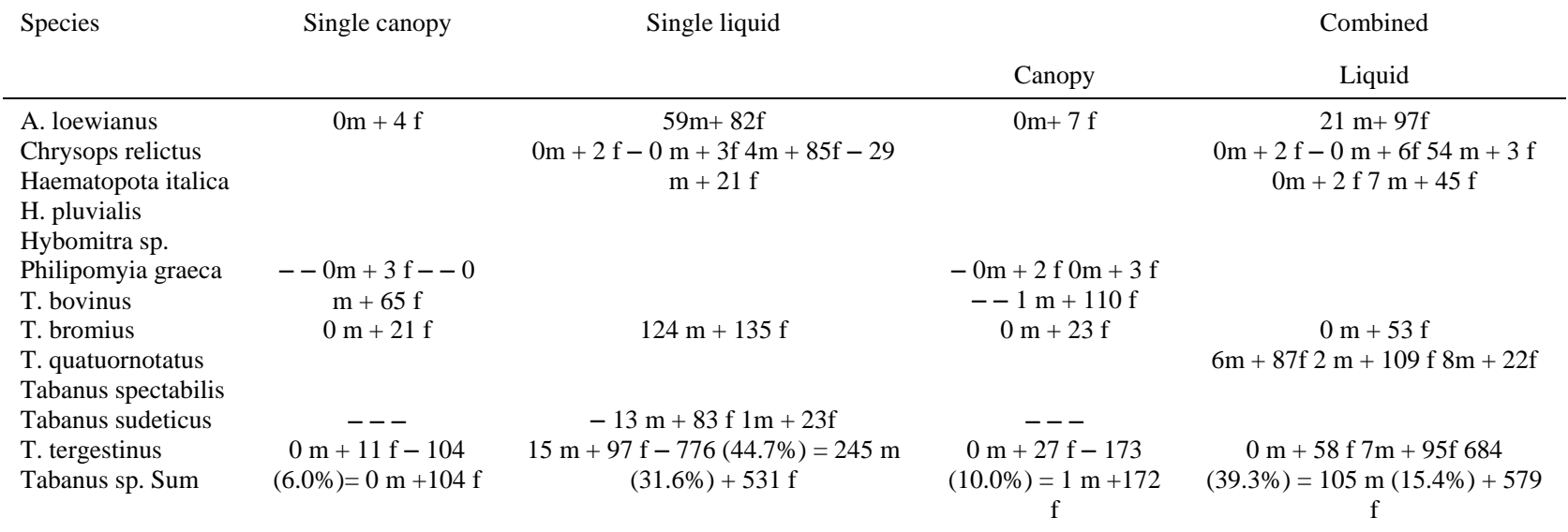

water surface. (iii) A combined trap composed of the canopy trap and the liquid trap below the canopy. The distance between the canopy trap and the combined trap was $15 \mathrm{~m}$, and the single liquid trap was between them in the middle. The tabanids captured by the liquid traps (table 4, fig. 3) were counted weekly (when the order of the traps was randomly changed), while the tabanids caught by the canopies (table 4) were counted only at the end of the experiment, since due to the construction of the canopies, their insect-collecting plastic containers could not have been emptied without the difficult and time-consuming mounting down of the canopies.

\section{Duration and repetition of experiments}

In our experiments, traps with different reflection- polarization characteristics captured tabanids, which were counted and removed periodically. Thus, the new arrivals were not influenced by the view of tabanid carcasses. Consequently, after tabanid counting actually a new replication of each experiment began. The number of replications $\mathrm{R}$ and the number of days $\mathrm{D}$ of a given experiment were: $\mathrm{R}=8+5, \mathrm{D}=62$ (experiment 1); $\mathrm{R}=7, \mathrm{D}=64$ (experiment 2); $\mathrm{R}=9, \mathrm{D}=75$ (experiment 3 ); $\mathrm{R}=13, \mathrm{D}=90$ (experiment 4). According to the results of our earlier quite similar field experiments with tabanids and tabanid traps (Kriska et al., 2009; Horváth et al., 2008, 2010a, b; Blahó et al., 2012a, b; Egri et al., 2012a, b, 2013), these numbers of replications and experimental days were large enough to detect significant differences.

\section{Identification of tabanids}

The tabanid flies captured in our experiments were conserved in ethyl alcohol. Using a binocular microscope (magnification: 50$100 \times$ ), their sex and species were identified later in the laboratory on the basis of the taxonomical features of Hungarian tabanid flies (Majer, 1987).

\section{Imaging polarimetric measurements}

The reflection-polarization characteristics of the tabanid traps used in our experiments (fig. 4) were measured by

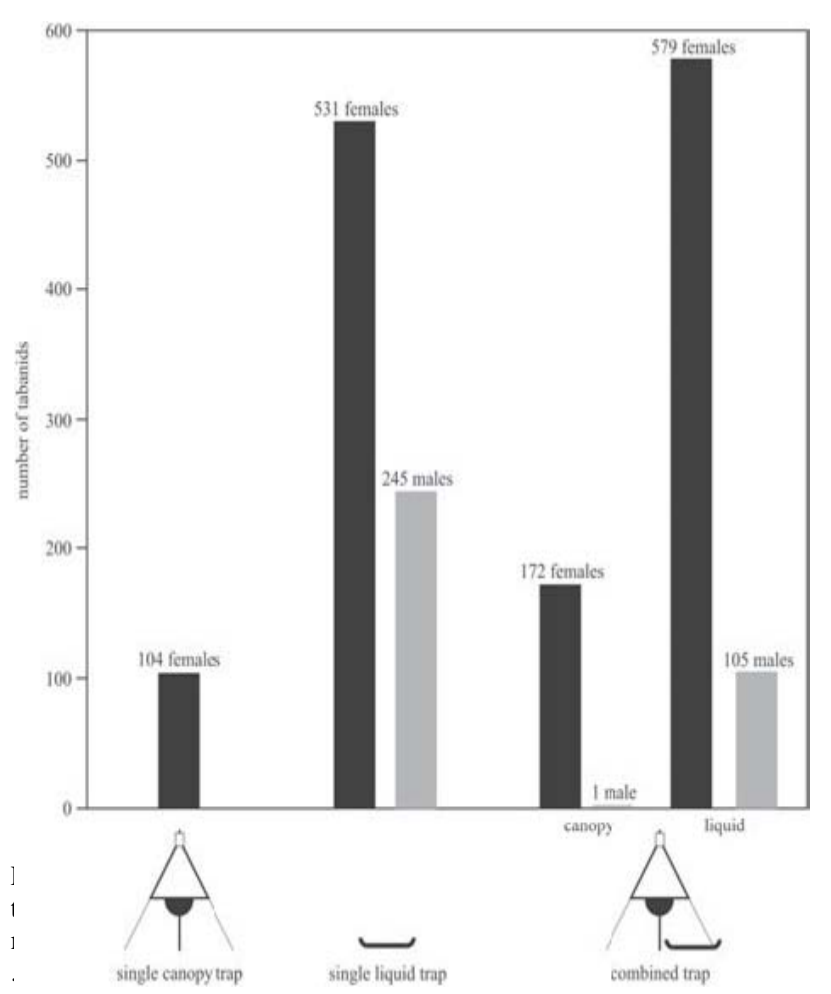

imaging polarimetry in the red $(650 \pm 40 \mathrm{~nm}=$ wavelength of maximal sensitivity \pm half bandwidth of the CCD detectors of the polarimeter), green $(550 \pm 40 \mathrm{~nm})$ and blue $(450 \pm 40 \mathrm{~nm})$ spectral ranges. The method of imaging polarimetry has been described in detail by Horváth \& Varjú $(1997,2004)$. Here we present only the polarization patterns measured in the blue part of the spectrum, since practically the same patterns were obtained in the red and green spectral ranges, because the trap surfaces were colourless (white or black), consequently, their reflection-polarization characteristics did not depend on the wavelength (e.g. red, green, blue) of light. 


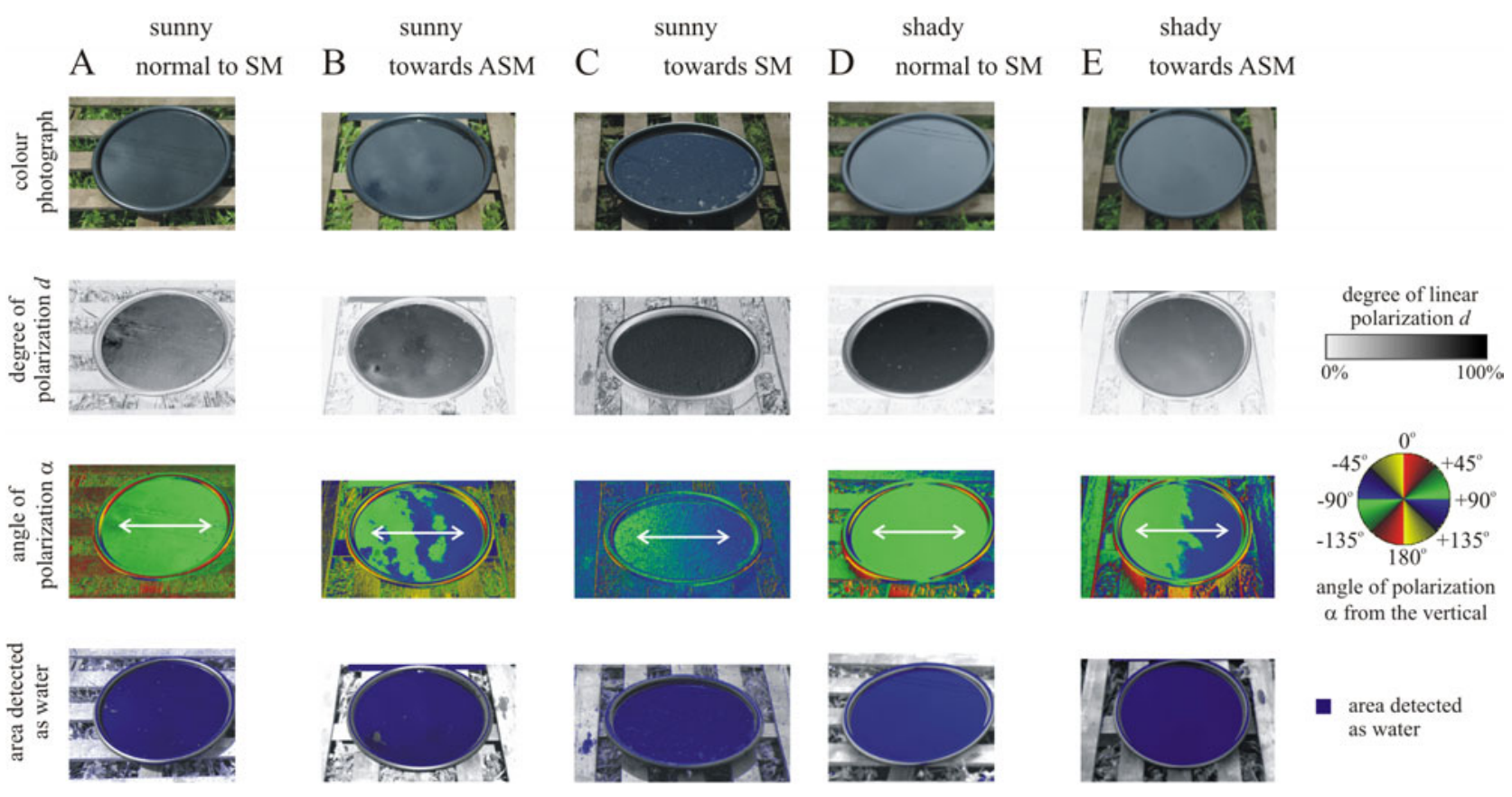

Fig. 4. Colour photograph, patterns of the degree of linear polarization $d$ and the angle of polarization $\alpha$ (clockwise from the vertical), and areas detected as water (for which the reflected light has the following characteristics: $\mathrm{d}>20 \%, 80^{\circ}<\alpha<100^{\circ}$ ) of a polarization liquid trap measured in the green part of the spectrum when it was sunny $(A-C)$ or shady $(D, E)$ for different directions of view relative to the solar meridian. Towards SM: the polarimeter saw towards the solar meridian. Towards ASM: the polarimeter saw towards the anti-solar meridian. Normal to SM: the polarimeter saw normal to the solar meridian. In the shady situation (D,E), the trap was illuminated by skylight from the totally overcast sky. The angle of elevation of the optical axis of the polarimeter was nearly $-35^{\circ}$ from the horizontal. In row 3, double-headed arrows show the local direction of polarization of light reflected from the horizontal oil surface.

\section{Statistical analyses}

The binomial $X^{2}$ tests (Zar, 2010) were performed with the use of the program Statistica 7.0. Since the distributions of our tabanid catches were too far from normal (which therefore cannot be compensated by any preliminary data transformation), parametric ANOVA tests could not be used.

\section{Results}

\section{Reflection-polarization characteristics of the liquid trap}

Fig. 4 shows the reflection-polarization characteristics of the polarization liquid trap when it is sunlit or shady measured from different directions of view relative to the solar meridian. These polarimetric measurements were performed to show that the liquid trap functions well under all illumination conditions: The light reflected from the sunlit horizontal shiny black oil surface is always horizontally polarized, independently of the viewing direction with respect to the sun. The degree of linear polarization $\mathrm{d}$ of oil-reflected light is higher or lower, depending on the elevation angle from the horizontal, but it is always high enough to attract polarotactic tabanids. Under overcast sky conditions the illumination of the liquid trap has approximately a rotational symmetry, and thus the reflection-polarization characteristics of the trap are independent of the viewing direction relative to the (invisible) sun, as can also be seen in fig. 4.Row 4 in fig. 4 displays the areas detected as water by polarotactic tabanid flies. Light with degrees of polarization $\mathrm{d}>20 \%$ and angles of polarization $80^{\circ}<\alpha<100^{\circ}$ is indicative of water for polarotactic tabanids (Kriska et al., 2009). In row 4 of fig. 4 , we can see that the shiny black horizontal oil surface reflects light with high degrees of polarization (represented by dark grey and black shades in the d-patterns of fig. 4), and with exactly or nearly horizontal direction of polarization (represented by bright green and blue colours in the $\alpha$-patterns of fig. 4). The consequence of these polarizing features is that the whole oil surface of the liquid trap is strongly attractive to polarotactic tabanids.

\section{Experiment 1 (height experiment 1)}

In experiment 1 (fig. 2A) performed in Göd only the polarization liquid trap on the ground (height $=0 \mathrm{~m}$ ) caught male and female tabanids $(\mathrm{N}=360)$, the other two elevated traps (height $=1$ and $2 \mathrm{~m}$ ) did not capture any tabanid flies (table 1 ). This is obviously a highly significant difference. In experiment 1 in Tarnalelesz (table 2), $98.5 \%(\mathrm{~N}=66)$ of the male and female tabanids were captured by the trap on the ground (height $\mathrm{H}_{0}=0 \mathrm{~m}$ ), the trap at $1 \mathrm{~m}$ above the ground $\left(\mathrm{H}_{1.0}=1.0 \mathrm{~m}\right)$ caught only one female tabanid fly, which is a statistically highly significant difference ( $\mathrm{H}_{0}$ versus $\mathrm{H}_{1.0}$ : $\mathrm{df}=1, \mathrm{X}^{2}$ $=63.06, \mathrm{P}<0.00001)$. The other two elevated traps $\left(\mathrm{H}_{0.5}=0.5 \mathrm{~m}\right.$ and $\mathrm{H}_{1.5}=1.5 \mathrm{~m}$ ) did not capture any tabanid.

\section{Experiment 2 (height experiment 2)}

In experiment 2 (fig. 2B, table 3) the polarization liquid trap on the ground (height $=0 \mathrm{~m})$ caught $94.3 \%(\mathrm{~N}=265)$ of 
Table 5. Statistical comparisons ( $X^{2}$ test) between the numbers of tabanids captured by the different traps (canopy trap with an aerial shiny black sphere, polarization liquid trap on the ground, combined trap: canopy trap together with liquid trap) in experiment 4 (fig. 2D, table 4). C1: single canopy trap with an aerial shiny black sphere. L1: single liquid trap on the ground. C2: canopy part of the combined trap. L2: liquid part of the combined trap.

\begin{tabular}{ll} 
Comparison of test surfaces & $\mathrm{X}^{2}$ test \\
\hline $\mathrm{C} 1$ versus L1 & $\mathrm{df}=1, \mathrm{X}^{2}=513.16, \mathrm{P}<0.00001$, \\
& significant $\mathrm{df}=1, \mathrm{X}^{2}=304.69, \mathrm{P}$ \\
& $<0.00001$, \\
C2 versus L2 & significant $\mathrm{df}=1, \mathrm{X}^{2}=0.30, \mathrm{P}<$ \\
$\mathrm{C} 1+\mathrm{L} 1$ versus C2 + L2 & 0.5810, \\
& not significant $\mathrm{df}=1, \mathrm{X}^{2}$ \\
$\mathrm{C} 1$ versus C2 + L2 & $=590.02, \mathrm{P}<0.00001$, \\
& significant
\end{tabular}

tabanids, while the elevated liquid trap (height $=20 \mathrm{~cm}$ ) on the top of a sticky black truncated conical skirt captured only 5.7\% (N=16) of tabanids. The single liquid trap on the ground caught significantly more tabanids than the elevated liquid trap at $20 \mathrm{~cm}$ from ground level together with its sticky black truncated conical skirt ( $\left.\mathrm{df}=1, \mathrm{X}^{2}=220.64, \mathrm{P}<0.00001\right)$. The sticky black truncated conical skirt of the elevated liquid trap caught much less tabanids $(0.7 \%)$ than the elevated liquid trap itself $(5.0 \%)$. This difference is statistically significant $\left(\mathrm{df}=1, \mathrm{X}^{2}=9, \mathrm{P}<0.0027\right)$.

According to our polarimetric measurements, the light reflected from the horizontal shiny black oil surface of both liquid traps used in experiment 2 (fig. 2B) was strongly polarized with high degrees of linear polarization $\mathrm{d}>70 \%$ with horizontal direction of polarization. On the other hand, the sticky black truncated conical skirt around the elevated liquid tray reflected not only horizontally, but also obliquely and vertically polarized light with higher ( $>50 \%$ ) or lower $(\mathrm{d}<50 \%)$ degrees of polarization. The consequence of these reflection-polarization characteristics was that only the strongly and horizontally polarizing oil surface of these traps could be visually attractive to polarotactic male and female tabanids.

\section{Experiment 3 (combined trap experiment 1)}

In experiment 3 (fig. 2C) the combined trap (composed of a canopy trap with a shiny black aerial sphere and a liquid trap on the ground) caught $71 \%$ [ $\mathrm{N}=568=$ canopy: 301 (37.6\%, all female Tabanus) + liquid: 267 (33.4\%, 145 female +122 male Tabanus sp.)] and the single canopy trap (canopy with an aerial shiny black sphere) captured $29 \%(\mathrm{~N}=232)$ of tabanids (all female Tabanus sp.), which is a statistically significant difference ( $\mathrm{df}=1, \mathrm{X}^{2}$ $=141.12, \mathrm{P}<0.00001)$. In the case of the combined trap used in experiment 3 (fig. 2C), the canopy captured slightly more (37.6\%, $\mathrm{N}=301)$ tabanids than the liquid trap (33.4\%, $\mathrm{N}=267)$, which is not a statistically significant difference $\left(\mathrm{df}=1, \mathrm{X}^{2}=2.04, \mathrm{P}<\right.$ 0.1537).

According to our polarimetric measurements, the white canopies of the canopy traps reflected practically unpolarized light (d $<10 \%$ ) with non-horizontal directions of polarization. The shiny black rubber sphere reflected strongly polarized light ( $\mathrm{d}>50 \%$ ) from its periphery, when the angle of reflection was near to Brewster's angle $\left[=\theta_{\text {Brewster }}=\arctan (n)\right.$ from the local normal vector of the spherical surface, where $n$ is the refractive index of rubber. The light component reflected at this angle from a surface is totally linearly polarized and its direction of propagation is perpendicular to that of the refracted component penetrating into the refractive medium]. Otherwise, the spherereflected light was only weakly polarized $(\mathrm{d}<50 \%)$. Furthermore, the direction of polarization of sphere-reflected light was always perpendicular to the horizontal, oblique or vertical plane of reflection, thus being vertically, obliquely or horizontally polarized, depending on the direction of view.

\section{Experiment 4 (combined trap experiment 2)}

Table 4 contains the species, sex and number of tabanids captured by the three different traps in experiment 4 (fig. 2D). The combined trap (canopy trap with liquid trap on the ground) caught 49.3\% ( $\mathrm{N}=857)$ of tabanids. The single liquid trap captured $44.7 \%(\mathrm{~N}=776)$ of tabanids, while the single canopy trap captured only $6.0 \%(\mathrm{~N}=104)$ of tabanids. These differences are statistically significant (table 5). The liquid trap part of the combined trap caught statistically significantly more tabanids $(\mathrm{N}=$ $684,39.3 \%)$ than the canopy trap part alone $(\mathrm{N}=173,10.0 \%)$. From these we conclude that the combined trap is (combined/single canopy $=857 / 104=$ ) 8.2 times more efficient than the classic canopy trap alone. According to table 4, the canopy traps captured practically only female tabanids, while the liquid traps caught both male (15.4-31.6\%) and female (68.4-84.6\%) tabanid flies. The percentages of males and females depended on the species.

\section{Discussion}

From the results of Kriska et al.(2009) it follows that the ideal colour of a polarization liquid trap is black, because only a horizontal, smooth, black surface reflects always strongly and horizontally polarized light, independently of the meteorological, illumination conditions (shady or sunlit) and direction of view (fig. 4). The physical reason for this is the effect of Umow (1905): in a given spectral range, the darker a reflecting surface is, the higher the degree of linear polarization of reflected light.

The advantage of our new polarization liquid trap is that it attracts both male and female tabanids by means of the strongly and horizontally polarized light reflected from the liquid surface (Horváth et al., 2008; Blahó et al., 2012a; Egri et al., 2012a, 2013). The mechanical trapping of tabanids touching the liquid surface is performed by a thin layer of oil being hydrophilic to the chitinous body of flies. The weather proofing of the trap is ensured by an overflow tube: if rain water falls into the tray, the rain drops sink below, the surplus water flows out through the tube, and the ideal horizontal smooth black oil surface remains intact. Furthermore, the oil layer on the water hinders the evaporation of water. The polarization liquid trap is a patented design in Hungary (Patent number P-07-00104: Polarization insect trap, especially tabanid trap).

In experiments 3 and 4 , we compared the tabanid-catching efficiencies of canopy traps, liquid traps and their combinations. We found that the combination of the canopy and liquid traps is much more efficient than the classic canopy trap alone: the combined trap captured 2.4 (experiment 3) and 8.2 (experiment 4) times more tabanids than the single canopy trap. The reason for the larger efficiency of the combined trap 
is that it captures simultaneously the host-seeking and the waterseeking tabanids (Horváth et al., 2008; Blahó et al., 2012a; Egri et al., 2012a, 2013). Due to these advantages, we suggest using the polarization liquid trap as an accessory of the traditional canopy trap capturing only the host-seeking female tabanids (Gressitt \& Gressitt, 1962; Catts, 1970; Wall \& Doane, 1980; Sasaki, 2001; Lehane, 2005; van Hennekeler et al., 2008; Egri et al., 2012a).

In our earlier field studies (Horváth et al., 2008; Kriska et al., 2009; Blahó et al., 2012a; Egri et al., 2012a), we experienced that tabanids may ignore horizontally polarizing surfaces placed above the ground level, because this is an unnatural situation (a water surface is generally on the ground level). Since this factor has not been systematically studied and is relevant to the positioning of our liquid trap, we conducted experiments 1 and 2. Another practical goal of these experiments was to test whether the liquid trap could be installed on an elevated mount in herds of cattle or horses. Such an elevated position of the trap could prevent the animals from stepping onto the trap.

In experiments 1 and 2, the liquid trap captured tabanids only when its oil surface was at ground level. One of the reasons for this finding may be that the liquid trap could imitate a horizontally polarizing water surface to polarotactic tabanids seeking water always at ground level, which is the natural situation. Remarkably, non-biting midges (chironomids) as polarotactic aquatic insects (Lerner et al., 2008) can also be trapped by elevated polarization liquid traps placed on the roof of a car at a height of about $1.5 \mathrm{~m}$ (Horváth et al., 2011). Another example is the case of dragonflies, which are also polarotactic (Wildermuth, 1998, 2007) and can be attracted by the horizontally polarizing elevated roofs of dark or red cars (Wildermuth \& Horváth, 2005). This could result from the heights at which the various species tend to fly, which might then determine whether they see the horizontally polarized light beneath them.

The ideal height of the liquid trap to capture maximal numbers of tabanids is the ground level. If the trap is elevated $(\geq 20 \mathrm{~cm})$, its tabanid-capturing efficiency is drastically reduced. Hence, the polarization liquid trap has to be settled on the ground to keep its large tabanid-catching efficiency. Thus, this trap must be installed in places where livestock cannot tread on it or drink the liquid (vegetable oil and water). Unfortunately, this trap cannot be installed on an elevated mount in herds of cattle or horses. The advantage of such an elevated mount would be that the animals could not step or drink into the liquid trap.

Egri et al.(2012a) showed that tabanids possess two different kinds of positive polarotaxis: (1) Female and male tabanids are attracted to horizontally polarized light. This polarotaxis is governed by the direction of polarization, and serves to detect water by means of the horizontal polarization of light reflected from the water surface. Male and female tabanids have to find water in order (i) to drink, (ii) to cool their body, and (iii) to find each other to copulate near water bodies. Furthermore, (iv) females need water to lay eggs on plants next to water or in mud. (2) Female tabanids have to suck blood of vertebrates to develop their eggs. Host animals are partly detected by the linearly polarized light reflected from the coats of hosts. The higher the degree of polarization, the more attractive is the host, independently of the direction of polarization of coat-reflected light (Egri et al., 2012a). This polarotaxis is governed by the degree of polarization, and serves to find host.
It is well known that the shiny black sphere of traditional canopy traps attracts exclusively female tabanids, since the sphere, hanging above the ground and beneath the canopy, imitates a host animal. Thus, canopy traps capture only female tabanids (Muirhead-Thomson, 1991; Lehane, 2005; Egri et al., 2012a, b, 2013). Egri et al.(2012a) also demonstrated that the sphere must be smooth (shiny), that is highly polarizing, in order to attract female tabanids efficiently. The reason for this may be that in nature the hosts of tabanids usually have relatively dark coats that polarize reflected light strongly. If the black sphere in a canopy trap is matte, i.e. non-polarizing or weakly polarizing, its tabanid-attracting capability is lost or drastically reduced (Egri et al., 2012a). These explain why only female tabanids are attracted to the shiny black spherical visual target of canopy traps, and which polarization characteristics attract them in different behavioural contexts. The Epps horsefly trap is composed of shiny black vertical panels with elongated trays filled with water containing soap to reduce surface tension (Watson et al., 2007). The efficacy of this trap should also be related to the polarization characteristics of reflected light. In environments with plentiful water, the efficacy of traps based on this concept may, however, be challenged.

Finally, we mention that in the combined trap the liquid trap component could be replaced by a horizontal sticky black board, which reflects also strongly and horizontally polarized light and it catches all tabanids touching its sticky surface as the horizontal black liquid surface. Such a polarization sticky trap (so-called 'horseflypaper') was recently designed and successfully tested by Egri et al.(2013).

In this work, we illustrated the relative improvement of the combined canopy-liquid trap over previous designs. In the future, it would be useful to know under what conditions this could matter to livestock producers. It would be worth investigating how the innovation in trap design suggested here (i) reduces the abundance of tabanids and disease transmission, or increases the quality of hides due to reduced biting scars. (ii) How does the impact depend on the density at which the combined traps are deployed? Only after such further studies guidance can be provided on how many combined traps might be needed in a given situation.

\section{Acknowledgements}

This work was supported by the grant TabaNOid 232366 (Trap for the Novel Control of Horse-flies on Open-air Fields) funded by the European Commission under the 7th Framework Programme received by G. Horváth and

G. Kriska. Gábor Horváth acknowledges the German Alexander von Humboldt Foundation for an equipment donation. Many thanks to Csaba Viski (Szokolya, Hungary) and István Simon (Göd, Hungary), who allowed our experiments on their horse farms. We are also grateful to Orsolya Buza and András Havasi (MFKK Invention and Research Center Services Co. Ltd, Budapest, Hungary) for their valuable help and advice in some field experiments. We thank two anonymous reviewers for their constructive comments.

\section{References}

Blahó, M., Egri, Á., Barta, A., Antoni, G., Kriska, G. \& Horváth, G. (2012a) How can horseflies be captured by solar panels? A new concept of tabanid traps using light 
polarization and electricity produced by photovoltaics.

Veterinary Parasitology 189, 353-365.

Blahó, M., Egri, Á., Báhidszki, L., Kriska, G., Hegedüs, R., Åkesson, S. \& Horváth, G. (2012b) Spottier targets are less attractive to tabanid flies: on the tabanid-repellency of spotty fur patterns. Public Library of $\begin{array}{lllll}\text { Science } & \text { ONE } & \text { (PLoS } & \text { ONE) } & 71138 .\end{array}$ doi:10.1371/journal.pone.0041138.

Bracken, G.K., Hanes, W. \& Thorsteinson, A.J. (1962) The orientation of horse flies and deer flies (Tabanidae: Diptera).

II. The role of some visual factors in the attractiveness of decoy silhouettes. Canadian Journal of Zoology 40, 689-695. Catts, E.P. (1970) A canopy trap for collecting Tabanidae. Mosquito News 30, 472-474.

Egri, Á., Blahó, M., Sándor, A., Kriska, G., Gyurkovszky, M., Farkas, R. \& Horváth, G. (2012a) New kind of polarotaxis governed by degree of polarization: attraction of tabanid flies to differently polarizing host animals and water surfaces. Naturwissenschaften 99, 407-416.

Egri, Á., Blahó, M., Kriska, G., Farkas, R., Gyurkovszky, M., Åkesson, S. \& Horváth, G. (2012b) Polarotactic tabanids find striped patterns with brightness and/or polarization modulation least attractive: an advantage of zebra stripes. Journal of Experimental Biology 215, 736-745.

Egri, Á., Blahó, M., Száz, D., Barta, A., Kriska, G., Antoni, G. \& Horváth, G. (2013) A new tabanid trap applying a modified concept of the old flypaper: linearly polarising sticky black surfaces as an effective tool to catch polarotactic horseflies. International Journal for Parasitology 43, 555-563.

Foil, L.D. (1989) Tabanids as vectors of disease agents. Parasitology Today 5,88-96.

Gressitt, J.C.L. \& Gressitt, M.K. (1962) An improved Malaise trap. Pacific Insects 4,87-90.

Harris, J.A., Hillerton, J.E. \& Morant, S.V. (1987) Effect on milk production of controlling muscoid flies, and reducing fly-avoidance behaviour by the use of Fenvalerate ear tags during the dry period. Journal of Dairy Research 54, 165-171.

Horváth, G. \& Kriska, G. (2008) Polarization vision in aquatic insects and ecological traps for polarotactic insects. Chapter 11, pp. 204-229 in Lancaster, J. \& Briers, R.A. (Eds) Aquatic Insects: Challenges to Populations. Oxon, UK, Wallingford, CAB International Publishing.

Horváth, G. \& Varjú, D. (1997) Polarization pattern of freshwater habitats recorded by video polarimetry in red, green and blue spectral ranges and its relevance for water detection by aquatic insects. Journal of Experimental Biology 200, 1155-1163.

Horváth, G. \& Varjú, D. (2004) Polarized Light in Animal Vision Polarization Patterns in Nature. Heidelberg, Berlin, New York, Springer-Verlag.

Horváth, G., Majer, J., Horváth, L., Szivák, I. \& Kriska, G. (2008) Ventral polarization vision in tabanids: horseflies and deerflies (Diptera: Tabanidae) are attracted to horizontally polarized light. Naturwissenschaften 95, 1093-1100.

Horváth, G., Blahó, M., Egri, Á., Kriska, G., Seres, I. \& Robertson, B. (2010a) Reducing the maladaptive attractiveness of solar panels to polarotactic insects. Conservation Biology 24, 1644-1653.

Horváth, G., Blahó, M., Kriska, G., Hegedüs, R., Gerics, B., Farkas, R. \& Åkesson, S. (2010b) An unexpected advantage of whiteness in horses: the most horsefly-proof horse has a depolarizing white coat. Proceedings of the Royal Society B 277, 1643-1650.
Horváth, G., Móra, A., Bernáth, B. \& Kriska, G. (2011) Polarotaxis in non-biting midges: female chironomids are attracted to horizontally polarized light. Physiology and Behavior 104, 1010-1015.

Hribar, L.J., LePrince, D.J. \& Foil, L.D. (1992) Ammonia as an attractant for adult Hybomitra lasiophthalma (Diptera: Tabanidae). Journal of Medical Entomology 29, 346-348.

Hunter, D.M. \& Moorhouse, D.W. (1976) The effects of Austrosimulium pestilens on the milk production of dairy cattle. Austrian Veterinary Journal 52,97-99.

Kriska, G., Bernáth, B., Farkas, R. \& Horváth, G. (2009) Degrees of polarization of reflected light eliciting polarotaxis in dragonflies (Odonata), mayflies (Ephemeroptera) and tabanid flies (Tabanidae). Journal of Insect Physiology 55, 1167- 1173.

Lehane, M.J. (2005) The Biology of Blood-Sucking in Insects. 2nd edn. Cambridge, UK, Cambridge University Press.

Lerner, A., Meltser, N., Sapir, N., Erlick, C., Shashar, N. \& Broza, M. (2008) Reflected polarization guides chironomid females to oviposition sites. Journal of Experimental Biology 211, 3536-3543.

Luger, S.W. (1990) Lyme disease transmitted by a biting fly. New England Journal of Medicine 322, 1752-1759.

Maat-Bleeker, F. \& van Bronswijk, J.E.M.H. (1995) Allergic reactions caused by bites from blood-sucking insects of the Tabanidae family, species Haematopota pluvialis (L.). [abstract]. Allergy 50 (Suppl. 26), 388.

Majer, J. (1987) Tabanids - Tabanidae. pp. 1-57 in Szekessy, V. (ed.) Fauna Hungariae. Budapest, Akadémiai Kiadó. Vol. 14. (in Hungarian).

Mihok, S. (2002) The development of a multipurpose trap (the Nzi) for tsetse and other biting flies. Bulletin of Entomological Research 92, 385-403.

Mihok, S. \& Lange, K. (2012) Synergism between ammonia and phenols for Hybomitra tabanids in northern and temperate Canada. Medical and Veterinary Entomology 26, 282-290.

Mihok, S. \& Mulye, H. (2010) Responses of tabanids to Nzi traps baited with octenol, cow urine and phenols in Canada. Medical and Veterinary Entomology 24, 266-272.

Mihok, S., Carlson, D.A., Krafsur, E.S. \& Foil, L.D. (2006) Performance of the Nzi and other traps for biting flies in North America. Bulletin of Entomological Research 96, 367-397.

Muirhead-Thomson, R.C. (1991) Trap Responses of Flying Insects: The Influence of Trap Design on Capture Efficiency. London, New York, Academic Press, Harcourt Brace Jovanovich Publishers.

Sasaki, H. (2001) Comparison of capturing tabanid flies (Diptera: Tabanidae) by five different color traps in the fields. Applied Entomology and Zoology 36, 515-519.

Thorsteinson, A.J., Bracken, G.K. \& Hanec, W. (1965) The orientation behaviour of horseflies and deerflies (Tabanidae: Diptera). III. The use of traps in the study of orientation of tabanids in the field. Entomologia Experimentalis et Applicata 8, 189-192.

Umow, N. (1905) Chromatische Depolarisation durch Lichtzerstreuung. Physikalische Zeitschrift 6, 674-676. van Hennekeler, K., Jones, R.E., Skerratt, L.F., Fitzpatrick, L.A., Reid, S.A. \& Bellis, G.A. (2008) A comparison of trapping methods for Tabanidae (Diptera) in North Queensland, Australia. Medical and Veterinary Entomology 22,26-31.

Veer, V., Parashar, B.D. \& Prakash, S. (2002) Tabanid and muscoid haematophagous flies, vectors of trypanosomiasis or surra disease in wild animals and livestock in Nandankanan 
Biological Park, Bhubaneswar (Orissa, India). Current Science 82, 500-503.

Wall, W.J. \& Doane, O.W. (1980) Large scale use of box traps to study and control saltmarsh greenhead flies (Diptera: Tabanidae) on Cape Cod, Massachusetts. Environmental Entomology 9, 371-375.

Watson, D.W., Denning, S.S., Calibeo-Hayes, D.I., Stringham, S.

M. \& Mowrey, R.A. (2007) Comparison of two fly traps for the capture of horse flies (Diptera, Tabanidae). Journal of Entomological Science 42, 123-132.

Wildermuth, H. (1998) Dragonflies recognize the water of rendezvous and oviposition sites by horizontally polarized light: a behavioural field test. Naturwissenschaften 85, 297-302.

Wildermuth, H. (2007) Polarotaktische Reaktionen von Coenagrion puella und Libellula quadrimaculata auf Erdbeerkulturen als ökologische Falle (Odonata: Coenagrionidae, Libellulidae). Libellula 26, 143-150.

Wildermuth, H. \& Horváth, G. (2005) Visual deception of a male Libellula depressa by the shiny surface of a parked car (Odonata: Libellulidae). International Journal of Odonatology 8, 97-105.

Zar, J.H. (2010) Biostatistical Analysis. New Jersey, USA, Pearson Prentice-Hall. 